This article was downloaded by: [University of New Hampshire]

On: 9 March 2009

Access details: Access Details: [subscription number 906511370]

Publisher Taylor \& Francis

Informa Ltd Registered in England and Wales Registered Number: 1072954 Registered office: Mortimer House, 37-41 Mortimer Street, London W1T 3JH, UK

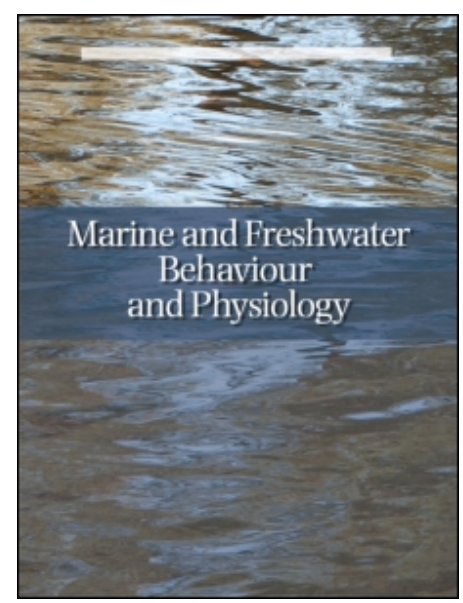

Marine and Freshwater Behaviour and Physiology

Publication details, including instructions for authors and subscription information:

http://www.informaworld.com/smpp/title content=t713644420

\title{
Home range dynamics of the American lobster, Homarus americanus
}

Darren A. Scopel a; Walter J. Golet a; Winsor H. Watson III a

a Zoology Department, University of New Hampshire, Durham, New Hampshire, USA

Online Publication Date: 01 January 2009

To cite this Article Scopel, Darren A., Golet, Walter J. and Watson III, Winsor H.(2009)'Home range dynamics of the American lobster, Homarus americanus',Marine and Freshwater Behaviour and Physiology,42:1,63 - 80

To link to this Article: DOI: $10.1080 / 10236240902781498$

URL: http://dx.doi.org/10.1080/10236240902781498

\section{PLEASE SCROLL DOWN FOR ARTICLE}

Full terms and conditions of use: http://www.informaworld.com/terms-and-conditions-of-access.pdf

This article may be used for research, teaching and private study purposes. Any substantial or systematic reproduction, re-distribution, re-selling, loan or sub-licensing, systematic supply or distribution in any form to anyone is expressly forbidden.

The publisher does not give any warranty express or implied or make any representation that the contents will be complete or accurate or up to date. The accuracy of any instructions, formulae and drug doses should be independently verified with primary sources. The publisher shall not be liable for any loss, actions, claims, proceedings, demand or costs or damages whatsoever or howsoever caused arising directly or indirectly in connection with or arising out of the use of this material. 


\title{
Home range dynamics of the American lobster, Homarus americanus
}

\author{
Darren A. Scopel, Walter J. Golet and Winsor H. Watson III* \\ Zoology Department, University of New Hampshire, Durham, New Hampshire, USA \\ (Received 13 August 2008; final version received 27 January 2009)
}

\begin{abstract}
A fixed array ultrasonic telemetry system was used to track the fine scale movements of American lobsters, Homarus americanus, within a large enclosure (mesocosm, $3125 \mathrm{~m}^{2}$ ). Positions of lobsters were obtained continuously, at $5 \mathrm{~min}$ intervals, for an average of 4.1 days. A kernel method was used to estimate the daily home ranges $(95 \%$ utilization distribution, UD), core areas of activity ( $50 \%$ UD) and distance traveled by each lobster. The mean home range size for all lobsters was $760.1 \pm 132.0 \mathrm{~m}^{2}(n=32)$, and the average core area was $74.0 \pm 10.9 \mathrm{~m}^{2}$. Home range size was closely correlated with the daily distance traveled by lobsters $\left(523.2 \pm 78.1 \mathrm{~m} \mathrm{day}^{-1} ; r^{2}=0.62, p=0.0001\right)$. Within the size range of lobsters used in this study $(62-93 \mathrm{~mm}$ carapace length), there was no correlation between the lobster sizes and the areas of their home ranges. Lobsters changed core areas and home ranges often, occupying $1.4 \pm 0.1$ different core areas each day. However, despite changing their core areas, the size of their home ranges remained fairly consistent from one day to the next. These data illustrate both the residential and the nomadic nature of lobster movements and demonstrate the utility of fixed array ultrasonic telemetry for quantifying the fine-scale movements of lobsters.
\end{abstract}

Keywords: American lobster; Homarus americanus; home range; ultrasonic telemetry; tracking

\section{Introduction}

Determining how an animal moves through, and utilizes its environment is fundamental to understanding its biology and ecology. Small-scale daily movement patterns are indicative of habitat requirements, foraging needs, territoriality, predator-prey relationships and reproductive activities (Pittman and McAlpine 2003). One commonly used measure of the space utilized by an animal is its home range. While several definitions of home range have been suggested (Burt 1943; Anderson 1982), for this study we have chosen the following definition, taken from Kernohan et al. (2001): "A home range is an area with a defined probability of an animal occurring within it during a specified time period." While home range is essentially a spatial measurement, the consideration of its time domain is critical in making behavioral or ecological inferences. In this investigation of the home range of the American lobster, Homarus americanus, we based our analyses on the area occupied by a lobster during a single day (24h).

*Corresponding author. Email: win@unh.edu 
Most lobster species are very mobile and their movements have been studied in detail using both tag/recapture and ultrasonic telemetry techniques. These studies have consistently shown that: (1) most lobsters, within the time frame that they were tracked, remained in the vicinity of the area where they were initially tagged, or traveled $<5 \mathrm{~km}$; and (2) in any given habitat or area there appear to be lobsters that are either residents or transients (spiny lobsters: Panulirus argus [Herrnkind and McLean 1971; Herrnking 1980]; Jasus edwardsii [Kelly 2001; Kelly and MacDiarmid 2003; Linnane et al. 2005]; Panulirus cygnus [MacArthur et al. 2008]; clawed lobsters: Homarus gammarus [Smith et al. 1998]; Homarus americanus [Dow 1974; Watson et al. 1999; Bowlby et al. 2007]; reviewed by Cooper and Uzmann 1980, Krouse 1980, Haakonsen and Anoruo 1994, Lawton and Lavalli 1995, Childress and Jury 2006). Additional studies have used the distance a displaced lobster will travel to reach its shelter or a baited trap as a technique for estimating a lobster's home range. For example, based on "the maximum distance of displacement... from where lobsters returned to their home patch", Lozano-Álvarez et al. (2002) estimated that the home range of $P$. guttatus had a radius of $100 \mathrm{~m}$. Using a similar approach, the home range of $P$. argus has been estimated to have a radius between 10 and $100 \mathrm{~m}$ (summarized in Herrnkind 1980); while the home range of adult P. cygnus likely has a radius of $150 \mathrm{~m}$ (Jernakoff et al. 1987), and the radius of the home range for juvenile P. cygnus appears to be $<15 \mathrm{~m}$ (Chittleborough 1974). Given the abundance of tracking data indicating that most lobsters do not travel more than $5 \mathrm{~km}$ during the course of several months, these estimates are quite reasonable. While most of these estimates are based on data gathered over a time frame of weeks to months, some are the result of daily observations. Our goal in this study was to investigate the fine-scale movements of lobsters on a daily basis, using a telemetry system that provided hundreds of positional fixes each day, thus allowing for a more rigorous calculation of home range sizes and core areas.

While the home ranges of terrestrial species have been rigorously measured by taking advantage of modern telemetry, GPS and ArcView technologies, our knowledge of the movement patterns and home ranges of mobile marine species is very limited, especially with respect to invertebrates (Hooge and Eichenlaub 1997; Pittman and McAlpine 2003). This gap in our understanding is primarily due to the challenges inherent in continuously observing marine species for long periods of time. To date, there have been only a few investigations related to the issue of decapod home ranges that have taken advantage of ultrasonic telemetry technologies (Clifton et al. 1970; Herrnkind 1980; Jarvis 1989; van der Meeren 1997; Watson et al. 1999) and even fewer that have obtained sufficient positional fixes to allow accurate calculations of home ranges. Since these studies were carried out with crabs and the time period used in each was different, it is difficult to compare these data with lobster home ranges and the findings presented in this report. For example, in 2002, Stone and O'Clair tracked 16 ovigerous Dungeness crabs (Cancer magister) for 97-378 days. Position data were collected once per week using a hand-held directional hydrophone. It was determined that the home ranges of these crabs, during the 3-12 month period, ranged from 22,706 to $2,095,728 \mathrm{~m}^{2}$ and that smaller crabs had the largest home ranges. In another study, Guerra-Castro et al. (2007) used manual ultrasonic telemetry to estimate the home ranges of two species of swimming crabs (Arenaeus cribrarius and Callinectes ornatus). Home range estimations were based on 3-21 positions for each animal, collected over the course of 10 days. The home range of $A$. cribrarius ranged from 3632 to $331,165 \mathrm{~m}^{2}$ and for C. ornatus 
it ranged from 934 to $43,030 \mathrm{~m}^{2}$, and home range size did not correlate with animal size for either crab. Based on these few studies it appears that decapod home ranges vary considerably, and that the relationship between animal size and home range size may be more complex than in terrestrial species (McNab 1963; Pittman and McAlpine 2003; Jetz et al. 2004).

The development of fixed array ultrasonic telemetry technology has made it possible to continuously and accurately measure the position of mobile aquatic species for days to weeks at a time. Thus, while previous manual telemetry studies of American lobsters have demonstrated that they tend to move intermittently, alternating periods of rapid movements $\left(0.3-1.8 \mathrm{~km} \mathrm{day}^{-1}\right)$ with $1-2$ weeks of more residential behavior (Jarvis 1989; Watson et al. 1999; Bowlby et al. 2007), it is now possible to quantify their daily movements during the time they are "residents" and occupy a more defined home range. This is best illustrated by a recent investigation that used a fixed array telemetry system to document the biological rhythms of American lobsters within a large mesocosm. In this study Golet et al. (2006) found that lobster movements in their natural habitat are much more complex than expected and that, despite a tendency by the general population to be most active at night, their daily rhythms were quite variable. The work described in this article takes advantage of the same mesocosm and telemetry techniques to investigate lobster home ranges.

The major goal of this study was to measure the daily home ranges and core areas of activity for American lobsters over a range of size classes (62-93 mm carapace length, CL). We determined that lobsters changed core areas of activity every 2-3 days and that males and females have home ranges of a similar size. Finally, within the narrow size range examined, there was no relationship between home range size and lobster size.

\section{Methods}

\section{Study site}

This study took place in a cove just offshore of Newcastle Island, New Hampshire, USA (see Figure 1, Golet et al. 2006). The mean depth in this area is $8 \mathrm{~m}$, with an average tidal fluctuation of $3 \mathrm{~m}$. The substrate within the study site consists of two distinct types; sand and fine sediment $(75 \%)$ and eelgrass beds $(25 \%)$. During the course of the study (May-October) bottom temperature fluctuated both tidally and seasonally and ranged from 8 to $19^{\circ} \mathrm{C}$. Current was monitored intermittently with an acoustic current meter (Model 2DACM; Falmouth Scientific Inc. Cataumet, MA, USA) positioned $1 \mathrm{~m}$ above the bottom in the center of the enclosure. Current speed ranged from 0.03 to $28.9 \mathrm{~cm} \mathrm{~s}^{-1}$ and the direction was predominately $\mathrm{NE}$, with short periods of SE flow during the middle stage of an outgoing tide.

\section{Mesocosm}

All tracking studies were conducted within a large $3125 \mathrm{~m}^{2}$ underwater enclosure (mesocosm). The size of the mesocosm was a compromise between a need to allow lobsters to move as much as possible, and the practical considerations of both building the mesocosm and excluding commercial and recreational traps from the area. We conducted a year of preliminary studies, without using an enclosure. 

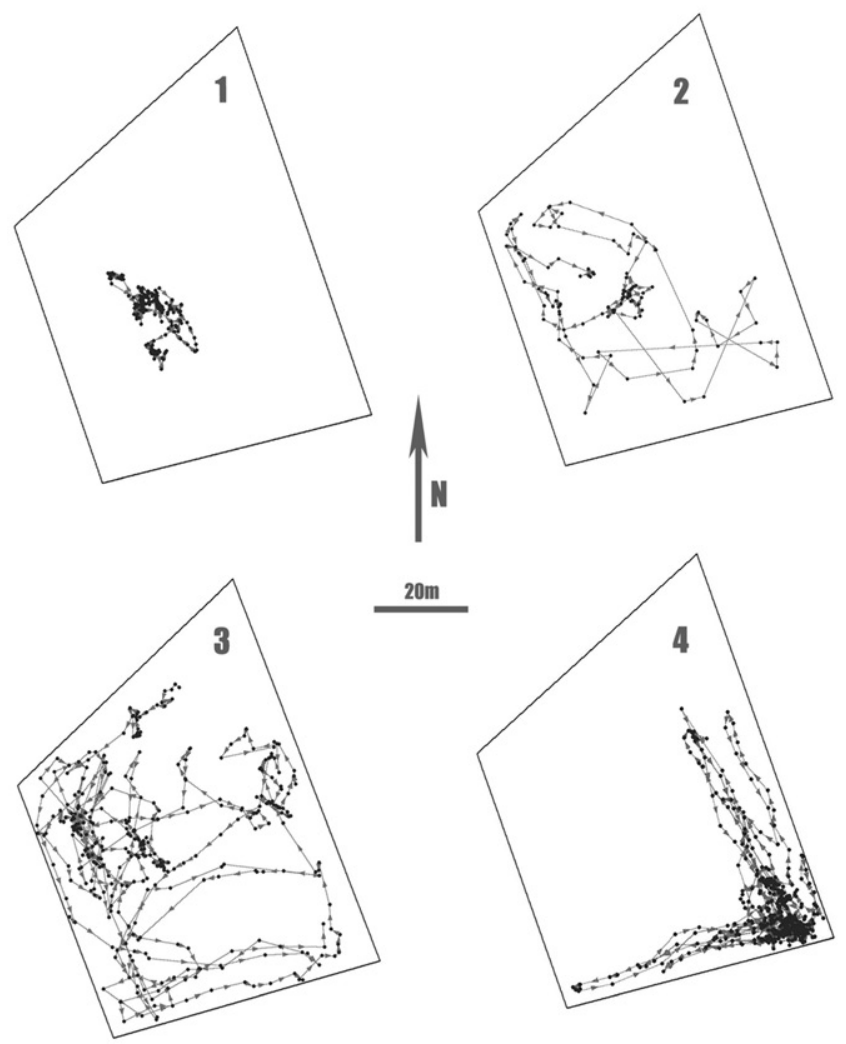

Figure 1. Homarus americanus. Four general types of movements expressed by lobsters within the mesocosm. Each panel displays the movements of one lobster during a single day. Movement types were defined according to the degree of interaction with the border of the enclosure. Type 1: little or no interactions with the border, with $<5-10 \%$ of the points located within $5 \mathrm{~m}$ of the fence. Type 2: some interaction with the border, with $<50 \%$ of the points located within $5 \mathrm{~m}$ of the fence. Type 3: transitional movements, with $50 \%-75 \%$ of points located within $5 \mathrm{~m}$ of the fence. Type 4: fence limited, with $>75 \%$ of the points located within $5 \mathrm{~m}$ of the fence. Type 4 days were excluded from home range estimations.

These preliminary studies indicated that typical lobster home ranges were less than the area of the mesocosm, while at the same time demonstrating that a mesocosm was necessary for the reasons listed below. The mesocosm was constructed from standard lobster trap material (12 gauge vinyl-coated wire, with $4 \times 4 \mathrm{~cm} \mathrm{mesh})$. The walls of the enclosure were $50 \mathrm{~cm}$ high with a $32 \mathrm{~cm}$ lip $\left(25 \mathrm{~cm}\right.$ bent at an angle of $45^{\circ}$, with the remaining $7 \mathrm{~cm}$ bent down parallel with the wall). Eight PVC "shelters" were secured to the bottom, four in the middle of the enclosure and one midway down each of the four walls. There was also a ghost trap near the middle of the enclosure that was not removed so that it could serve as an additional shelter. See Golet et al. (2006) for further details concerning the design and construction of the mesocosm.

The construction of a mesocosm was necessary in order to keep the lobsters within the range of the fixed array telemetry system for several days in a row. In addition it: (1) kept the lobsters within the central, highest resolution, area of the tracking system; (2) allowed for the efficient location of lobsters and recovery of 
transmitters after each tracking period was completed; (3) made it possible to simultaneously track multiple lobsters; and (4) prevented lobsters from interacting with traps, because lobstermen refrained from fishing traps inside the enclosure. Additional benefits and drawbacks of using a mesocosm for a study of this nature are summarized in Golet et al. (2006). It should be noted that, while the mesocosm allowed mobile species, such as lobsters, flounders, crabs and striped bass to readily enter, it limited the ability of those that could not swim, to easily leave. In addition, over time, sessile species and drifting algae accumulated on the fence and this created a refuge for a number of species. Therefore, the enclosure altered the community structure in its immediate vicinity, but it did not significantly change the overall abundance of either lobster prey species or predators.

\section{Tracking system}

A commercially available radio-acoustic positioning telemetry system (VRAP model, VEMCO Ltd., Halifax, Canada), consisting of a three-buoy array and base station, was deployed at the site. The buoys were moored $\sim 150 \mathrm{~m}$ apart in an equilateral triangle. Each buoy had a radio that allowed it to communicate with an onshore base station (receiver/computer) that was located in a building $\sim 300 \mathrm{~m}$ from the study site. The buoys listened to each transmitter for $25 \mathrm{~s}$ and then relayed the data to the base station. The computer then triangulated the position of each transmitter based upon the signal arrival times of each pinger to each of the buoys. The position of each transmitter was calculated every 2-5 min and was accurate to $\pm 1-3 \mathrm{~m}$ while within the central portion of buoy array (O'Dor et al. 1998). (A complete description of the tracking system can be found in Klimley et al. 2001; Golet et al. 2006.)

\section{Tagging protocol}

Each lobster was tagged with a continuous, ultrasonic transmitter (V8SC-2L, VEMCO Ltd., $28 \times 9 \mathrm{~mm}, 3 \mathrm{~g}$ in water). Each transmitter was identified by its unique, fixed frequency $(63-84 \mathrm{kHz})$ and emitted a pulse every $2 \mathrm{~s}$. Lobsters were captured inside the mesocosm and tagged by SCUBA divers in situ. The transmitters were prepared prior to diving by gluing them inside a $15 \mathrm{~mm}$ section of Tygon ${ }^{\circledR}$ tubing through which a cable tie was inserted. Underwater they were secured around the dorsal carapace of each lobster by connecting the cable tie between the second and the third pair of walking legs. The tagging process took $2-3 \mathrm{~min}$ and each lobster was immediately released at the point of capture. The smallest animal tracked $(62 \mathrm{~mm} \mathrm{CL})$ weighed $\sim 220 \mathrm{~g}$; therefore the transmitter was $\sim 1.3 \%$ of its body weight. This is well within the generally accepted value of $2 \%$ body weight that has been established for fish tracking studies (Baras and Lagardere 1995; Jepsen et al. 2002). We observed no apparent difference in the movements of lobsters tagged using this method in comparison to other lobsters in the vicinity that were not tagged. We have been using this method for several years and we have documented lobsters moving over $10 \mathrm{~km}$ with a harness of this type. In addition, we have repeatedly filmed lobsters that have been residents in one area after being fitted with a transmitter harness and they do not display any apparent change in behavior and only rarely we have observed them attempt to remove the harness or slip out of it (Pictures and videos of lobsters equipped with transmitters can be seen 
at www.lobsters.unh.edu.). Furthermore, a laboratory study was conducted to determine if the tagging method affected the distance traveled by a lobster. In this experiment, 10 lobsters ( 5 males $/ 5$ females, 83-94 mm CL) were tagged, placed inside a $2 \mathrm{~m}$ diameter ring ("racetrack") located inside a $4 \mathrm{~m}$ seawater tank and videotaped with a time-lapse recorder for 3-4 days. The tag was then removed and their movements were recorded for an additional 3-4 days. Distance traveled was calculated by watching the videotapes and counting the number of times they walked around the "racetrack" in $24 \mathrm{~h}$. There was no significant difference between the distance traveled by tagged and the untagged lobsters (paired $t$-test, $p=0.819$ ).

Upon completion of each trial, divers located each lobster with an underwater hydrophone/receiver, removed the transmitter and released the lobster outside of the mesocosm. A total of 63 lobsters, ranging from 62 to $93 \mathrm{~mm}$ in CL, were tracked between June and October of 2002 and 2003. Typically, four lobsters (2 males and 2 females) were tracked simultaneously for five days. In an effort to gauge the effect of buoy movement on home range estimations, a single reference transmitter (model $\mathrm{V} 16,90 \times 16 \mathrm{~mm}$ ) was anchored in the center of the mesocosm and its position was determined every $10 \mathrm{~min}$ for the duration of the study.

Due to ambient noise levels (boat traffic, wind, waves, and current), lobsters residing in crevices, and tidal shifts of the buoy array, spurious points were often generated by the system. Therefore, prior to calculating home ranges, the data were filtered using gain and noise levels, arrival times of pulses and the average number of pulses received by each buoy (detailed methods can be found in Golet et al. 2006). This filtering method removed $\sim 64 \%$ of the positions, yielding an average of 248 positions/day for each lobster.

\section{Home range calculations}

The daily home ranges of lobsters were calculated using the Animal Movement Analysis Extension (AMAE) (Hooge and Eichenlaub 1997) for ArcView 3.3 (ESRI, Redlands, CA, USA). A day began at 0:00 a.m. and ended at 12:00 midnight (if days were divided into periods between sunset and sunrise, results were not statistically different). The first and last days were not used for analyses because data were not collected on these days for a full $24 \mathrm{~h}$ (lobsters were typically tagged and recaptured in the middle of a day). In addition, we avoided using the first day of data because some animals exhibited a post-handling response that did not appear to be

a part of their typical daily activity. This post-handling response has been observed in other lobster studies as well, and it typically consists of extensive movements, often in the direction of deeper water (see "Discussion"). The home range for each day that an animal was tracked was calculated using the fixed kernel function within the AMAE. This method is a probabilistic calculation that generates a utilization distribution (UD), that describes the probability of finding an animal within a given area (Worton 1987; Seaman and Powell 1996). Since a kernel estimation is based on the density of points, it is not as affected by outliers as are some other methods of estimating home range. Another significant advantage of using kernel estimation is that it can identify multiple areas of activity, which allow for a better characterization of an animal's use of space (Samuel et al. 1985). In this study, the 50\% UD was used to designate the core area of activity and the $95 \%$ UD was used to designate the daily home range. In an effort to keep the home range estimations as accurate as possible, any day that 
had less than 50 positions was not included (Seaman et al. 1999). Due to the intensive sampling regime used in this study, the level of autocorrelation between points was significant. However, we decided that efforts to correct for this, such as sub-sampling, would unnecessarily reduce the sample size and significantly dilute the accuracy and precision of the data (De Solla et al. 1999).

Kernel estimations require the selection of a smoothing parameter to determine the degree of smoothing that will occur along the perimeter of each home range. Least squares cross validation (LSCV) has frequently been suggested as an effective method for smoothing kernels (Worton 1989; Seaman and Powell 1996; Seaman et al. 1999). However, LSCV has been shown to have a high failure rate for datasets with large sample sizes and tight clustering (Hemson et al. 2005; Gitzen et al. 2006). Furthermore, a comparison of lobster home range areas smoothed using LSCV and an ad hoc value generated by the AMAE, showed no significant difference between the two methods. Therefore the ad hoc value was chosen as a smoothing parameter for all home ranges in this study.

\section{Results}

A total of 63 lobsters were tagged and tracked during the summers of 2002 and 2003. Data from 25 of these lobsters were not used for the analyses presented in this article because the transmitter failed, lobsters died or they escaped prior to being tracked for at least $24 \mathrm{~h}$. After plotting the movement paths for the remaining 38 lobsters, it became evident that the border of the mesocosm may have had more of an influence on lobster movements on some days, than on other days (Figure 1). In order to focus our analyses on lobsters that appeared to be residents, and whose movements were not overly constrained by the enclosure, we classified every day of movement, by every lobster, into four types. During Type 1 days, lobsters had little or no interaction with the fence, while during Type 4 days lobsters appeared to be in a transition mode and their movements were highly focused in the SE corner of the mesocosm and were determined to be highly constrained by the fence. Types 2 and 3 days were intermediate between Types 1 and 4 (Figure 1). Based on this categorization, all Type 4 days, for any lobster, were removed from consideration for subsequent analysis. Six of 38 lobsters were omitted from the study since they demonstrated Type 4 movement for the entire time that they were tracked. Thus, the analyses presented here are based on tracking data from 140 complete days, obtained from 32 lobsters, when they were expressing Types 1, 2, or 3 patterns of activity. It should be noted that a separate analysis of this dataset (Golet et al. 2006) determined that there was no significant difference in the temporal movement patterns of lobsters between the movements types described above.

Home range size and distance traveled per day were calculated for every lobster, for each $24 \mathrm{~h}$-time period that they were tracked. The mean duration of tracking for each lobster was $4.4 \pm 0.3$ days (range $=2-10$, SEM used here and throughout the results unless indicated otherwise). The average daily home range area (95\% UD) for all lobsters was $760.1 \pm 132.0 \mathrm{~m}^{2}$, which was $24 \%$ of the area of the mesocosm. A typical home range of about this size, along with the path traveled by this lobster during the $24 \mathrm{~h}$ period, is illustrated in Figure 2. The average core area of activity $\left(50 \%\right.$ UD) was $74.0 \pm 10.9 \mathrm{~m}^{2}$. There were no significant differences in the mean home range sizes measured in each month or year of the study (ANOVA, $p>0.05$ ). 


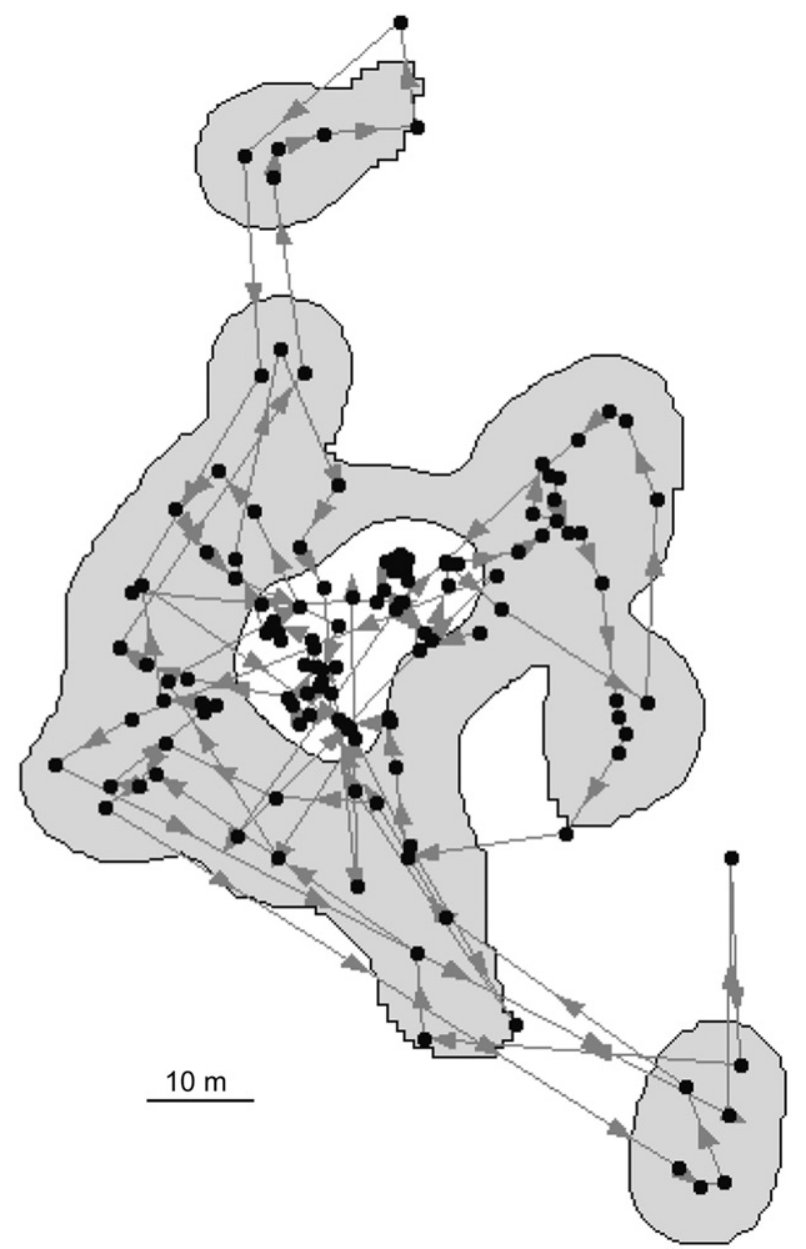

Figure 2. Homarus americanus. Kernel home range estimation of a $78 \mathrm{~mm}$ CL female lobster. The $95 \%$ UD (outer gray contour) is $1214 \mathrm{~m}^{2}$ and the $50 \%$ UD (inner white contour) is $130 \mathrm{~m}^{2}$. Contours are overlaid upon the actual track of this lobster during the same time period. Each dot is one-positional fix.

The distance traveled per day by each lobster, and by the reference pinger, was calculated using Arcview/AMAE. The distance that the reference pinger traveled in a given day was then subtracted from the distance that a given lobster traveled during the same day in order to compensate for errors caused by buoy movements. The average daily distance traveled for all lobsters was $523.2 \pm 78.1 \mathrm{~m} \mathrm{day}^{-1}$. There was a good correlation $\left(r^{2}=0.62, p=0.0001\right)$ between the mean distance traveled by individual lobsters and the mean size of their home range (Figure 3).

The average size of the lobsters used in the study was $76.6 \pm 1.4 \mathrm{~mm} \mathrm{CL}$ (range 62-93 mm CL). Over the size range studied, there was no correlation between lobster size and home range area (Figure $4 \mathrm{a}$; correlation coefficient $r^{2}=0.005$ ); slope of the line not significantly different from zero $(p=0.69))$. There was also no correlation between the lobster size and the distance moved per day $\left(r^{2}=0.008\right.$, $p=0.63$; Figure 4b). 


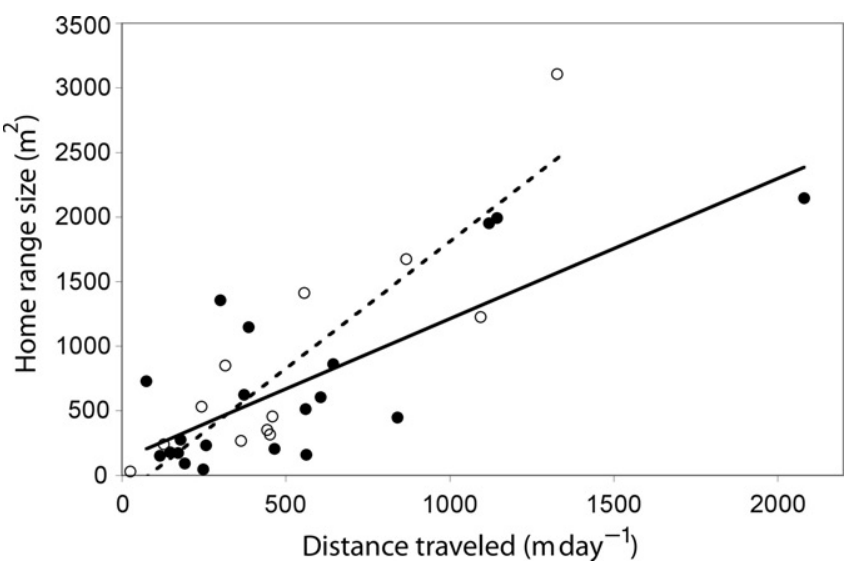

Figure 3. Homarus americanus. The relationship between the average distance traveled by a lobster in a day and the average daily home range area of the same lobster. Data were obtained from a total of 32 lobsters and each lobster was tracked for $\sim 4$ days. Females are represented by open circles and the dashed line; males are represented by closed circles and the solid line. Lobsters that moved the furthest also had the largest home ranges. There was a significant relationship between the size of a home range and the distance traveled by both male $\left(r^{2}=0.6\right)$ and female $\left(r^{2}=0.8\right)$ lobsters, either when analyzed separately, or as a group $\left(r^{2}=0.6\right)$.

No statistically significant difference existed between the area of male and female home ranges $(p=0.27$, unpaired $t$-test), even though female home ranges $\left(871.1 \pm 252.0 \mathrm{~m}^{2}\right)$ tended to be larger than male home ranges $\left(693.5 \pm 151.0 \mathrm{~m}^{2}\right)$. Likewise, no significant difference ( $p=0.77$, unpaired $t$-test) was found between the mean distance traveled by male $\left(523.5 \pm 107.5 \mathrm{mday}^{-1}\right.$, range $\left.=75-2081 \mathrm{~m} \mathrm{day}^{-1}\right)$ and female lobsters $\left(522.8 \pm 112.1 \mathrm{~m} \mathrm{day}^{-1}\right.$, range $\left.25-1328 \mathrm{~m} \mathrm{day}^{-1}\right)$. There was also no significant difference in the mean size of the males $(n=20)$ versus the females $(n=12)$ (males $=78.3 \pm 1.9 \mathrm{~mm}$ CL; females $=73.8 \pm 1.8 \mathrm{~mm} \mathrm{CL} ; p=0.06$, unpaired $t$-test), used in this study. Within each sex there was also no correlation between size and home range area (male, $r^{2}=0.02$, female, $r^{2}=0.02$ ). However, as a group, large males tended to have the smallest home ranges (note that many of the largest males in Figure 4 had small home ranges).

Many lobsters had more than one core area in a given day (mean $=1.4 \pm 0.1$; range $=1-4)$. For example, the lobster depicted in Figure 5 had one core area on days 1,3 , and 5 and two cores areas on days 2,4 , and 6 . While there was a significant difference ( $p=0.02$, unpaired $t$-test) in the number of core areas/day between males $(1.2 \pm 0.1)$ and females $(1.6 \pm 0.2)$, there was no correlation between the size of a lobster and the number of core areas/day, either as a group $\left(r^{2}=0.039, p=0.27\right)$, or by sex (males, $r^{2}=0.019, p=0.55$; females, $r^{2}=0.003, p=0.85$ ). Lobsters often traveled repeatedly between daily core areas, and it was not uncommon for them to revisit core areas of the previous days (Scopel et al. in preparation). However, when a lobster changed core areas within a given day, $51 \%$ of them were unique and had not been occupied previously by that lobster during the time period that it was being tracked. This was true for lobsters as a group $(0.7 \pm 0.1$ unique core areas/day), as well as for males $(0.6 \pm 0.1)$ and females $(0.8 \pm 0.1)$. While females established 

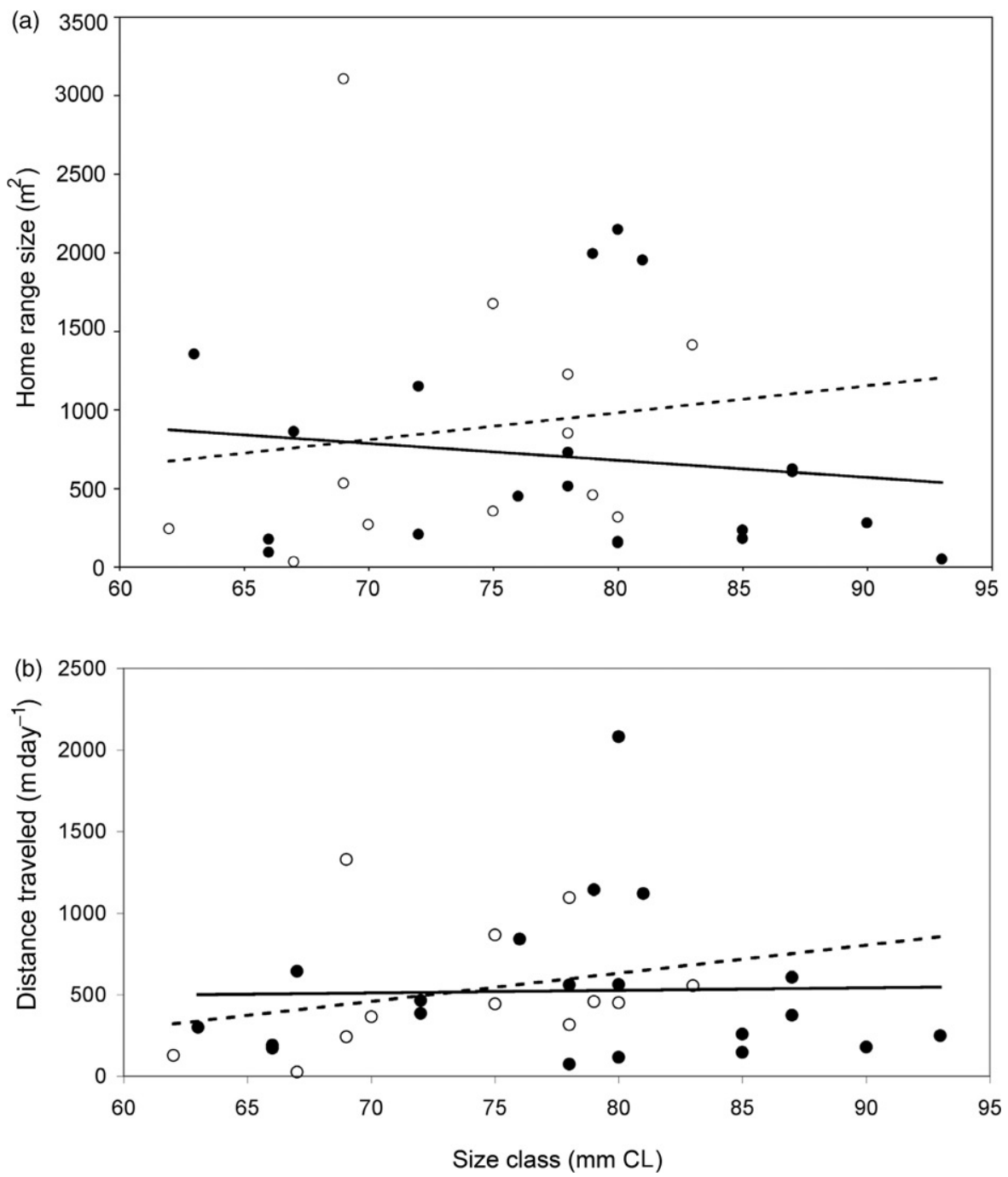

Figure 4. Homarus americanus. The relationship between lobster size and (a) the mean size of their home range and (b) the mean distance they traveled per day. Females are represented by open circles and the dashed line; males are represented by closed circles and the solid line. In both cases the size of the lobster had no significant influence on the size of their home range $\left(r^{2} ;\right.$ females $=0.02$, males $\left.=0.02\right)$ or how far they traveled $\left(r^{2}\right.$; females $=0.08$, males $=0.0008)$.

more unique core area/day than males, the difference between them was not quite significant ( $p=0.06$, unpaired $t$-test).

As described above, while lobsters often had multiple core areas in a given day, they were all not unique to that day and lobsters often used some core areas for several days. On average they occupied a given core area for $2.4 \pm 1.6$ (SD) days (range $=1-6$ ). For example, the lobster in Figure 5 occupied four distinct core areas in 6 days (averaging 1.5 days in each core area). Interestingly, despite changing core area locations, and thus home ranges, a number of lobsters had home ranges of 


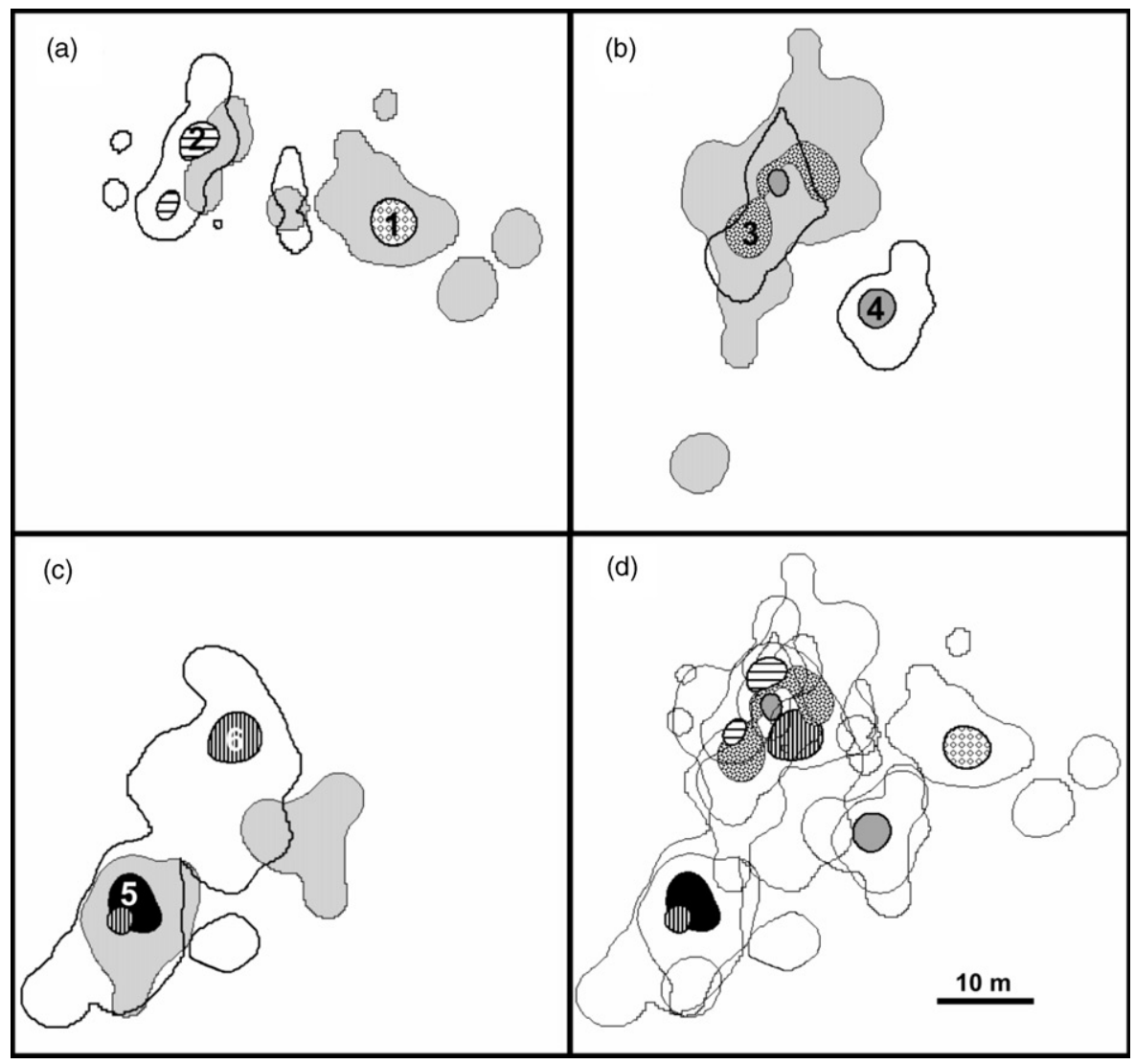

Figure 5. Homarus americanus. This figure represents six consecutive home ranges (95\% UD) and core areas (50\% UD) for a $79 \mathrm{~mm}$ CL female lobster. Figures (a)-(c) each contain two UDs, the first $95 \%$ UD is shaded and second is outlined. The largest $50 \%$ UD for each day is numbered. Figure (d) is a composite of all 6 days and only the 50\% UDs are shaded. The $95 \%$ UD areas are; day $1=314$, day $2=183$, day $3=524$, day $4=278$, day $5=341$, and day $6=726 \mathrm{~m}^{2}$.

similar sizes during the time that they were being tracked (Figure 6). Only five lobsters kept the same home range for the entire time they were tracked and these were all mature males. One of these lobsters was cohabitating with a female and one resided in and around the ghost trap.

\section{Discussion}

While large-scale American lobster movements have been investigated for many years, this is one of the first investigations of their fine-scale movements. The use of fixed array ultrasonic telemetry techniques made it possible to quantify all the movements made by 32 lobsters for several consecutive days at a time. As a result, accurate calculations of rates of movement, home range sizes, and shifts of core areas could be made. The resulting data support the view that lobsters typically express one of the following activity states: nomadic, transitional, or residential. Moreover, it illustrates that individual lobsters are continually shifting their home ranges and core 


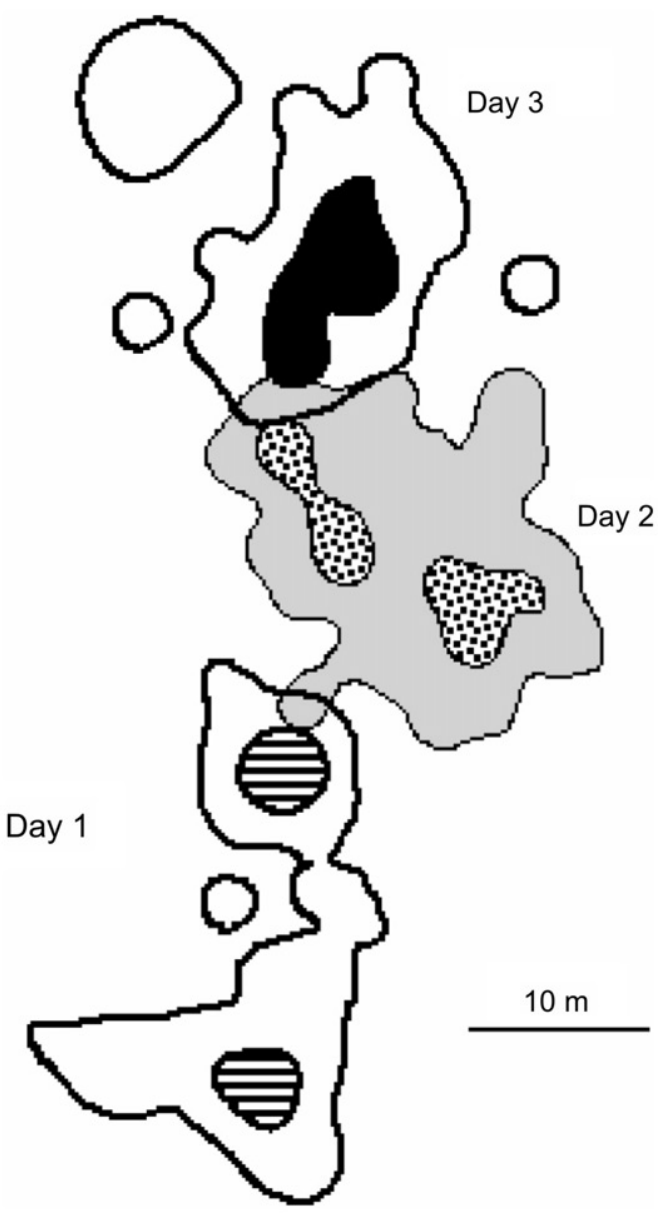

Figure 6. Homarus americanus. Home ranges for three consecutive days, obtained from a $62 \mathrm{~mm} \mathrm{CL}$ female. Both $95 \%$ and $50 \%$ UDs are shown. Note: the $95 \%$ UD for each day was comparable $\left(\right.$ day $1=259$, day $2=296$ and day $3=236 \mathrm{~m}^{2}$.

areas (most likely shelters or pits), thus expressing both nomadic and residential behavioral states within the same day. Based on these data, and ongoing investigations of lobster movements outside of a mesocosm, we propose that lobsters are facultative shelter dwellers or express facultative homing behavior. That is, while they are capable of homing back to the same shelter repeatedly, and thus occupying the same home range and core area for many days in succession, they do not consistently exhibit this behavior. While the underlying reasons for this pattern of behavior are probably quite complex, we propose that, unlike many other species with excellent homing capabilities, such as bees and ants, lobsters do not have to return to the exact same shelter in order to survive. Therefore, if they are evicted, or return to find another lobster in their shelter, they often seek another shelter rather than defend their "home".

It is generally accepted that, for terrestrial animals, home range size scales with animal size because larger animals require more food and thus larger areas for foraging (McNab 1963; Reiss 1988; McLoughlin and Ferguson 2000). 
Currently, there is no consensus about whether this holds true for aquatic animals and to our knowledge this issue has not been addressed in aquatic invertebrates because of the paucity of information about their home ranges. The available data for several decapod species indicate that there is a relatively poor correlation between locomotor activity, home range size, and animal size. Some studies found no relationship (Watson et al. 1999; Gherardi et al. 2000; Comeau and Savoie 2001; Stone and O'Clair 2002; Cooke 2004; Golet et al. 2006), while others found smaller animals moved farther (Kelly and MacDiarmid 2003; Linnane et al. 2005). In this study, due to the size of the transmitter, the smallest lobster we could track was $62 \mathrm{~mm} \mathrm{CL}$, and due to availability in our study area, the largest was $93 \mathrm{~mm}$ CL. Thus, while this size range covered both sexually mature and immature lobsters, the range was relatively small in comparison to the size range of lobsters residing in the Gulf of Maine. Nevertheless, while it is likely that very small lobsters move little, and very large lobsters move the greatest distances, it is interesting that on a daily basis juvenile lobsters are just as likely to travel long distances as sexually mature individuals.

There are many factors that may influence the tendency of lobsters to leave their core area and move about their environment. First, they have an endogenous rhythm of locomotion, so that even when confined in a running wheel (Jury et al. 2005), or on a treadmill (O'Grady et al. 2001) they walk several hundred meters each day, primarily at night. Second, during a certain portion of the summer they might be looking for mates or searching for optimal mating shelters. The tendency for large males to move less than other males or females might be related to their mating behavior (Cowan 1991). Third, lobsters might be foraging for food, but very little is known about how much they eat, how far they must travel to find appropriate prey and whether they must capture prey each day. Fourth, it is possible that smaller lobsters may actually require more food resources during certain times of year than larger lobsters, because they are growing faster and molting more frequently. This might, in part, explain why there is a tendency for some smaller lobsters and crabs to have larger home ranges. Finally, smaller lobsters might be less capable of defending a shelter and, as a result, they are evicted from shelters more often and must search for a new shelter. We often observed this type of behavior in our study area, using time-lapse video surveillance. Golet et al. (2006) suggested that the frequent shelter evictions might contribute to the wide variety of daily patterns of behavior recorded from lobsters in same area. Clearly, in order to fully appreciate the factors that most strongly influence the home range sizes of crustaceans, we must learn more about the activities they are performing inside and outside of their core areas.

In our previous studies of lobster movements we used a hand-held system and obtained positional fixes every day with an accuracy that we estimated to be in the range of $20 \mathrm{~m}$ (Watson et al. 1999). We found that lobsters appeared to stay in the same areas for a week or so, and then move rapidly to a new area. This same pattern has been documented in other lobster species as well (reviewed in Herrnkind, 1980; Lawton and Lavalli 1995; Childress and Jury 2006). Thus, while the daily home ranges of the lobsters in our previous study, as well as many lobster species, were $<1000 \mathrm{~m}^{2}$, their weekly or monthly home ranges, which included the transitions from one general area to another, were much larger (but generally $<1 \mathrm{~km}^{2}$ ). Until it becomes routine to define the time frame of home range investigations, scientists will continue to find it difficult to compare their results.

In the current study, using a fixed array ultrasonic telemetry system to investigate daily movements in more detail, it became clear that when lobsters appear to be 
resident in one specific area for a period of time they were, in fact, quite active and probably moving from one shelter or core area to another. The term "neighborhood" could be used to describe an area inhabited by a lobster for several days to weeks, during which time it occupies a series of overlapping home ranges. It appears, both from this study, our previous investigation of lobster movements in the Great Bay estuary (Watson et al. 1999) and our ongoing investigation of lobster movements outside the mesocosm (unpublished results) that many lobsters are nomadic, facultative shelter dwellers; alternating residence in a neighborhood for 1-2 weeks, with rapid excursions to a new neighborhood. This same pattern of intermittent movements and nomadic behavior has also been observed in two species of crayfish (Gherardi et al. 2000; Robinson et al. 2000). Further studies of other crustaceans, using high-resolution fixed array ultrasonic telemetry may reveal that this pattern of behavior is quite common in this group of animals.

It is very difficult to compare the home range sizes of different species because the time and spatial scales, as well as the tracking techniques, vary considerably between studies. For example, previous studies have estimated the home range of various lobster species to have radii between 10 and $150 \mathrm{~m}\left(314-70,650 \mathrm{~m}^{2}\right)$, while the average home range $\left(760.1 \pm 132.0 \mathrm{~m}^{2}\right)$ of lobsters in this study falls at the lower end of this range. However, a significant part of the discrepancy in these data is likely the result of both differing tracking techniques and sampling intervals. With a fixed-array system, it is possible to obtain hundreds of positions a day for each animal, while with manual-tracking methods, obtaining one position each day is often a challenge. Our preliminary data from lobsters outside the mesocosm indicates that, while their daily home range is comparable to what we obtained inside the mesocosm, when calculated on a weekly basis it increases an order of magnitude to values approaching those reported for Dungeness crabs and some lobster species. Thus, if we strive to be able to compare home ranges between species, and in different habitats, it is important to make it an accepted practice to calculate home ranges based on distincttime domains, such as a day, a week or a month, as well as basing estimates on a minimum number of locations for each time period.

This study was conducted inside a large mesocosm because it was the best way to obtain sufficient high-resolution data, using fixed-array ultrasonic telemetry methods, while at the same time avoiding the confounding influence of traps (which were not present inside the mesocosm). The pros and cons of using this approach have been discussed at length in Golet et al. (2006). The biggest limitation of this approach is that the fence may reduce the size of some home ranges. Nevertheless, the data presented appear to be representative of normal lobster behavior for the following reasons. First and foremost, our preliminary studies tracking lobsters in the same area, but outside the mesocosm, have yielded very similar, but more limited, results. Outside the mesocosm most lobsters change core areas on a daily basis, the size of the home ranges are similar to those measured inside the mesocosm, and they periodically make long excursions to a new area, or "neighborhood". While we continue to investigate the behavior of lobsters outside the mesocosm in order to test the conclusions presented in this article, most of the data obtained to date are consistent with those collected inside the mesocosm. Second, if lobsters spent a great deal of time near the southeast corner of the mesocosm during a given day, termed Type 4 days, we eliminated those data from the dataset since they were not expressing typical behaviors of residents. These lobsters were not simply wandering around aimlessly since their movement was very much focused in the SE direction. 
Our interpretation of this behavior is that it was a transitional state and was an attempt to move a long distance toward deeper water (located SE of mesocosm), or to a new "neighborhood". Several of the lobsters that were tagged during this study moved in the SE direction for a brief period $(<24 \mathrm{~h})$ after being handled. This behavior was also expressed by the majority of lobsters that escaped the mesocosm. Transitional movements of this type appear to be a common post-handling response in lobsters (Lund et al. 1973; Jernakoff 1987; Jernakoff et al. 1987) and we have additional data indicating that most lobsters move directly toward deeper water after being handled. Therefore, some lobsters were, in fact, restricted from moving in one direction for a significant distance on some days and we eliminated many of these days from our home range analyses. In contrast, the mesocosm did not appear to drastically alter the normal behavior of most lobsters, on most days, especially with regard to homing, home ranges and daily patterns of activity. That being said, we are fully aware that our findings must be viewed conservatively until we are able to obtain additional data from lobsters whose movements are not limited by an enclosure.

One of the most surprising findings in this study was that lobsters changed core areas very often. The literature is rich with accounts of lobster shelter affinity and a number of scientists have reported seeing the same lobsters in a given shelter on many occasions over stretches for a week or more (Cobb 1971; Ennis 1984; Karnofsky et al. 1989). In our study only five lobsters retained the same core area for the whole time that they were tracked and these were all larger males. As stated above, many lobsters may have changed core areas because they were evicted from their shelters and, if this is the case, then larger males may have been more capable of defending their shelters. Or, large males may have been defending a shelter for the purpose of mating. While shelters were somewhat limited in this area, the use of pits in the sand and eelgrass beds as refuges along this region of the $\mathrm{NH}$ coastline is not unusual. Moreover, even lobsters that escaped the mesocosm and wandered into rocky habitats changed core areas on approximately a daily basis. Finally, long-term observations of American lobsters in, and around, their shelters by Dr Robert Steneck (personal communication) along the coast of Maine, reinforce the view that lobsters are somewhat nomadic, changing shelters often. Except perhaps for the mating season, when male lobsters appear to guard shelters, it may be that a certain portion of the population frequently moves from one home range to the next, rather than spending time defending a territory and/or a shelter. This pattern of changing core areas may be a common feature of crustacean behavior that scientists will appreciate better as more precise ways are developed to monitor the movements of these aquatic invertebrates.

\section{Acknowledgments}

We would like to thank all the students and colleagues who helped us with building the mesocosm, diving and other aspects of this study. These people include Chris Rillahan, Emily Weed, Adam Chouinard, Liz Kintzing, Nate Reynolds, Noel Carlson, Susan Little, Lisa Bedford, Heidi Pye, Ben Winslow, and Jen Wishinski. In addition, we would like to express our gratitude to the numerous NH lobstermen who kindly refrained from fishing their traps inside and around the mesocosm during the course of this study. We would also like to express our appreciation to National Marine Fisheries Service for allowing us to use part of their office for a telemetry base station and Jesse Phillips and Joy Stronk for assistance analyzing portions of the data. This study was funded by a USDA Hatch grant (WHW) 
and a UNH Center for Marine Biology grants (DS). This is contribution 478 from Center for Marine Biology/Jackson Estuarine Laboratory series.

\section{References}

Anderson DJ. 1982. The home range: a new nonparametric estimation technique. Ecology. 63:103-112.

Baras E, Lagardere JP. 1995. Fish telemetry in aquaculture: review and perspectives. Aquacult Int. 3:77-102.

Bowlby HD, Hanson JM, Hutchings JA. 2007. Resident and dispersal behavior among individuals within a population of American lobster Homarus americanus. Mar Ecol Prog Ser. 331:207-218.

Burt WH. 1943. Territoriality and home range concepts as applied to mammals. J Mammalogy. 24:346-352.

Childress MJ, Jury SH. 2006. Behaviour. In: Phillips BF, editor. Lobsters: biology, management, aquaculture and fisheries. Oxford, UK: Blackwell Publishing. p. 78-112.

Chittleborough RG. 1974. Home range, homing and dominance in juvenile western rock lobsters. Aust J Mar Freshwat Res. 25:227-234.

Clifton HE, Mahnken CVW, van Derwalker JC, Waller RA. 1970. Tektite 1, man-in-the-sea project: marine science program. Science. 168:659-663.

Cobb JS. 1971. The shelter-related behavior of the lobster Homarus americanus. Ecology. 52:108-115.

Comeau M, Savoie F. 2001. Movement of American lobster (Homarus americanus) in the southwestern Gulf of St. Lawrence. Fisheries Bull. 100:181-192.

Cooke SM. 2004. The effects of temperature on the physiology and locomotory behavior of the American lobster, Homarus americanus. [PhD dissertation]. [Durham (NH)]: University of New Hampshire.

Cooper RA, Uzmann JR. 1980. Ecology of juvenile and adult Homarus. In: Cobb JS, Phillips BF, editors. Vol. 2. The biology and management of lobsters. New York: Academic Press. p. 97-142.

Cowan DF. 1991. The role of olfaction in courtship behavior of the American lobster, Homarus americanus. Biol Bull. 181:402-407.

De Solla SR, Bonduriansky R, Brooks RJ. 1999. Eliminating autocorrelation reduces biological relevance of home range estimates. J Anim Ecol. 68:221-234.

Dow RL. 1974. American lobsters tagged by Maine commercial fishermen, 1957-1959. Fish Bull. 72:622-623.

Ennis GP. 1984. Territorial behavior of the American lobster, Homarus americanus. Tran Am Fish Soc. 113:330-335.

Gherardi F, Barbaresi S, Salvi G. 2000. Spatial and temporal patterns in the movement of Procambarus clarkii, an invasive crayfish. Aquat Sci. 62:179-193.

Gitzen BA, Millspaugh JJ, Kernohan BJ. 2006. Bandwidth selection for fixed kernel analysis of animal utilization distributions. J Wildl Manage. 70(5):1334-1344.

Golet WJ, Scopel DA, Cooper AB, Watson WH. 2006. Daily patterns of locomotion expressed by American lobsters (Homarus americanus) in their natural habitat. J Crustac Biol. 26:610-620.

Guerra-Castro E, Carmona-Suárez CA, Conde JE. 2007. Activity patterns and zonation of the swimming crabs Arenaeus cribrarius and Callinectes ornatus. J Crustac Biol. 27:49-58.

Haakonsen HO, Anorou AO. 1994. Tagging and migration of the American lobster Homarus americanus. Rev Fish Sci. 2(1):79-93.

Hemson G, Johnson P, South A, Kenward R, Ripley R, MacDonald D. 2005. Are kernels the mustard? Data from global positioning system (GPS) collars suggests problems for kernel home-range analyses with least-squares cross-validation. J Anim Ecol. 74:455-463. 
Herrnkind WF. 1980. Spiny lobsters: patterns of movement. In: Cobb JS, Phillips BF, editors. Vol. I. The biology and management of lobsters. New York: Academic Press. p. 349-407.

Herrnkind WF, McLean R. 1971. Field studies of orientation, homing, and mass emigration in the spiny lobster, Panulirus argus. Annals of the New York Acad of Sci. 188:359-377.

Hooge PN, Eichenlaub B. 1997. Animal movement extension to Arcview. Anchorage, AK, USA: Alaska Science Center - Biological Science Office, US Geological Survey.

Jarvis C. 1989. Movement patterns of late-state ovigerous female lobsters (Homarus americanus Milne-Edwards) at Jeddore, Nova Scotia. [MS thesis]. [Halifax, Nova Scotia, Canada]: Dalhousie University.

Jepsen N, Koed A, Thorstad E, Baras E. 2002. Surgical implantation of telemetry transmitters in fish: how much have we learned? Hydrobiologia. 483:239-248.

Jernakoff P. 1987. Foraging patterns of juvenile Western Rock lobsters Panulirus cygnus George. J of Mar Biol Ecol. 113:125-144.

Jernakoff P, Phillips BF, Maller RA. 1987. A quantitative study of the nocturnal foraging distances of the Western Rock lobster Panulirus cygnus George. J of Mar Biol Ecol. 113:9-21.

Jetz W, Carbone C, Fulford J, Brown JH. 2004. The scaling of animal space use. Science. 306:266-268.

Jury SH, Chabot CC, Watson WH III. 2005. Daily and circadian rhythms of locomotor activity in the American Lobster, Homarus americanus. J Exp Mar Biol Ecol. 47:606-612.

Karnofsky EB, Atema J, Elgin RH. 1989. Field observations of social behavior, shelter use, and foraging in the lobster, Homarus americanus. Biol Bull. 176:239-246.

Kelly S. 2001. Temporal variation in the movement of the spiny lobster Jasus edwardsii. Mar Freshwat Res. 52:323-331.

Kelly S, MacDiarmid AB. 2003. Movement patterns of mature spiny lobsters, Jasus edwardsii, from a marine reserve. N Z J Mar Freshwat Res. 37:149-158.

Kernohan BJ, Gitzen RA, Millspaugh JJ. 2001. Radio tracking and animal populations. San Diego (CA): Academic Press. p. 125, Chapter 5, Analysis of animal space use and movements.

Klimley PA, Le Boeuf BJ, Cantara KM, Richert JE, Davis SF, Sommeran SV. 2001. Radioacoustic positioning as a tool for studying site-specific behavior of the white shark and other large marine species. Mar Biol. 138:429-446.

Krouse JS. 1980. Summary of lobster, Homarus americanus, tagging studies in American waters (1898-1978). Can Tech Rep Fish Aquat Sci. 932:135-140.

Lawton P, Lavalli KL. 1995. Biology of the lobster Homarus americanus. Postlarval, juvenile, adolescent and adult ecology. New York: Academic Press, Chap. 4, p. 47-81.

Linnane A, Dimmlich W, Ward T. 2005. Movement patterns of the southern rock lobster, Jasus edwardsii, off South Australia. N Z J of Mar Freshwat Res. 39:335-346.

Lozano-Álvarez E, Carrasco-Zanini G, Briones-Fourzán P. 2002. Homing and orientation in the spotted spiny lobster, Panulirus guttatus (Decapoda, Palinuridae), towards a subtidal coral reef habitat. Crustaceana. 75:859-873.

Lund WA, Stewart LL, Rathbun CJ. 1973. Investigation on the lobster. Final Report to the Department of Commerce. NOAA, NMFS, Comm Fish Res Dev Act, Connecticut, Proj. 3-130-R.

MacArthur LD, Babcock RC, Hyndes GA. 2008. Movements of the western rock lobster (Panulirus cygnus) within shallow coastal waters using acoustic telemetry. Mar Freshwat Res. 59:603-613.

McLoughlin PD, Ferguson SH. 2000. A hierarchical pattern of limiting factors helps explain variation in home range size. Ecoscience. 7:123-130.

McNab BK. 1963. Bioenergetics and the determination of home-range size. Am Nat. 97:133-140. 
O’Dor RK, Andrade Y, Webber DM, Sauer WHH, Roberts MJ, Smale MJ, Voegeli FM. 1998. Applications and performance of radio-acoustic positioning and telemetry (RAPT) systems. Hydrobiologia. 371/372:1-8.

O'Grady DF, Jury SH, Watson WH III. 2001. Use of a treadmill to study the relationship between walking, ventilation and heart rate in the lobster Homarus americanus. Mar Freshwat Res. 52:1387-1394.

Pittman SJ, McAlpine CA. 2003. Movements of marine fish and decapod crustaceans: process, theory and application. Adv Mar Biol. 44:205-294.

Reiss M. 1988. Scaling of home range size: body size, metabolic needs and ecology. Trends Ecol Evol. 3:85-86.

Robinson CA, Thom TJ, Lucas MC. 2000. Ranging behaviour of a large freshwater invertebrate, the white-clawed crayfish Austropotamobius pallipes. Freshwat Biol. 44:509-521.

Samuel MD, Pierce DJ, Garton EO. 1985. Identifying areas of concentrated use within the home range. J Anim Ecol. 54:711-719.

Seaman DE, Millspaugh JJ, Kernohan BJ, Brundige GC, Raedeke KJ, RA Gitzen. 1999. Effects of sample size on kernel home range estimates. J Wildl Manage. 63:739-747.

Seaman DE, Powell RA. 1996. An evaluation of the accuracy of kernel density estimators for home range analysis. Ecology. 77:2075-2085.

Smith IP, Collins KJ, Jensen AC. 1998. Electromagnetic telemetry of lobster Homarus gammarus (L.) movements and activity: preliminary results. Hydrobiologia. 371/372:133-141.

Stone RP, O'Clair CE. 2002. Behavior of female Dungeness crabs, Cancer magister, in a glacial southeast Alaska estuary: homing, brooding-site fidelity, seasonal movements, and habitat use. J Crustac Biol. 22:481-492.

van der Meeren GI. 1997. Preliminary acoustic tracking of native and transplanted European lobsters (Homarus gammarus) in an open sea lagoon. Mar. Freshwat Res. 48:915-921.

Watson WH, Vetrovs A, Howell WH. 1999. Lobster movement in an estuary. Mar Biol. 134:65-75.

Worton BJ. 1987. A review of models of home range for animal movements. Ecol Model. 38:277-298.

Worton BJ. 1989. Kernel methods for estimating the utilization distribution in home-range studies. Ecology. 70:164-168. 